\title{
DO EDITOR
}

DOI: 10.5380/rmu.v1i3.40744

"O papel das resinas trocadoras de íons na hipercalemia aguda com manifestação eletrocardiográfica é questionável, pois o tempo necessário para a ação da resina é incompatível com a rapidez necessária nesta situação que ameaça à vida". Esta é a conclusão do artigo de revisão da Professora Maria Aparecida Pachaly, da Disciplina de Nefrologia da UFPR, publicado nesta edição da RMU. A hipercalemia, definida como potássio sérico acima de $5,5 \mathrm{mEq} / \mathrm{L}$, constitui emergência clínica, que demanda rápido tratamento pelo médico atendente. Nesta revisão, a Dra. Maria Aparecida aborda de maneira crítica os tipos de resina disponíveis, seus benefícios e limitações. Leitura imperdível.

Dois artigos muito interessantes, resultado de palestras proferidas durante a Semana de Comemoração dos 100 anos da faculdade de Medicina da UFPR, também fazem parte desta edição. O professor Miguel Ibraim A. Hanna Sobrinho, chefe do DCM, aborda o tema Formação Médica e a Evolução do Curso de Medicina. E a chefe do Setor de Ciências da Saúde, professora Claudete Reggiani, discorre sobre o passado, presente e futuro do curso de Medicina da UFPR.

Boa Leitura,

Mauricio de Carvalho

Editor 